\title{
Carbonation Process to Manufacture Lithium Carbonate from Lithium Sulfate
}

\author{
Dong-Hyeon Choi and Jei-Pil Wang* \\ Department of Metallurgical Engineering, Pukyong National University, Busan 48513, Korea.
}

\begin{abstract}
This study focuses on producing $\mathrm{Li}_{2} \mathrm{CO}_{3}$ powder from $\mathrm{Li}_{2} \mathrm{SO}_{4}$, produced and concentrated from spodumene crystal through sulfuric acid method, by using carbonation reaction. Reaction was induced by combining carbon powder and $\mathrm{CO}_{2}$ gas for carbonation. The optimal experiment conditions were confirmed according to reaction temperature, reaction time, and the amount of carbonation mixture input. Lastly, $\mathrm{Li}_{2} \mathrm{CO}_{3}$ was selectively collected through water leaching. Purity of 99.93 wt.\% for collected $\mathrm{Li}_{2} \mathrm{CO}_{3}$ powder was confirmed through ICPOES analysis.
\end{abstract}

Keywords: Spodumene, Lithium sulfate, Lithium carbonate, Carbonation, Water leaching

\section{INTRODUCTION}

Lithium is a metal that is frequently used in various fields, including cathode material for secondary lithium-ion battery, raw material of light alloy for aircraft, and fuel for nuclear fusion power generation, with increasing regulations in response to global warming and climatic change, and advanced countries are in the process of developing electric automobiles to replace internal combustion engine vehicles that emit $\mathrm{CO}_{2}$. In order to develop electric automobiles, the development of secondary lithium battery for electric automobiles must take place essentially. Therefore, the demand for lithium is increasing with increasing researches and development for secondary lithium battery and secondary lithium battery for electric automobiles, and the global influence of lithium in general is expected to be significant ahead. [1-3]

Therefore, a stable supply system for lithium material needs to be established to secure competitiveness in the global market and develop domestic industry. Accordingly, studies on recovering valuable metals such as lithium, manganese, aluminum, and cobalt from batteries and lithium scraps, and collecting lithium from crystals like lepidolite and spodumene that contain lithium have been conducted, but the current level of technology is not nearly enough to supply for the amount of lithium that is consumed in Korea.[4-11]

Most of existing technologies in Korea on lithium recovery and production through recycling consist of separating and collecting lithium through leaching using acid solutions, such as D2EHPA, PC88A and nitric acid, or organic acids such as citric acid and oxyacid. [8-10] In case of lithium recovery using acid or basic liquid causes environmental pollution due to by- products and wastes generated during the process as it uses acid or basic solutions, and leads to problems such as waste disposal cost; therefore, an environment-friendly recycling or lithium recovery process needs to be developed without using acid or basic solution. [12-14]

Therefore, this study focused on separating and collecting $\mathrm{Li}_{2} \mathrm{CO}_{3}$ and oxides from lithium-containing spodumene through carbonation. After carbonation, the powder was separated into impurities and $\mathrm{Li}_{2} \mathrm{CO}_{3}$ through leaching and decompression filtration using distilled water. The study was conducted on producing high purity $\mathrm{Li}_{2} \mathrm{CO}_{3}$ powder from $\mathrm{Li}_{2} \mathrm{CO}_{3}$ solution through drying process.

\section{MATERIALS}

The material used in this study was $\mathrm{Li}_{2} \mathrm{SO}_{4}$, which was produced and concentrated from spodumene crystal through sulfuric acid method, and the analysis of raw sample was performed using XRD (X-ray Diffraction) method. Result of $\mathrm{XRD}$ analysis is displayed in Fig. 1, and the analysis confirmed that the phase of raw material was $\mathrm{Li}_{2} \mathrm{SO}_{4}$ phase.

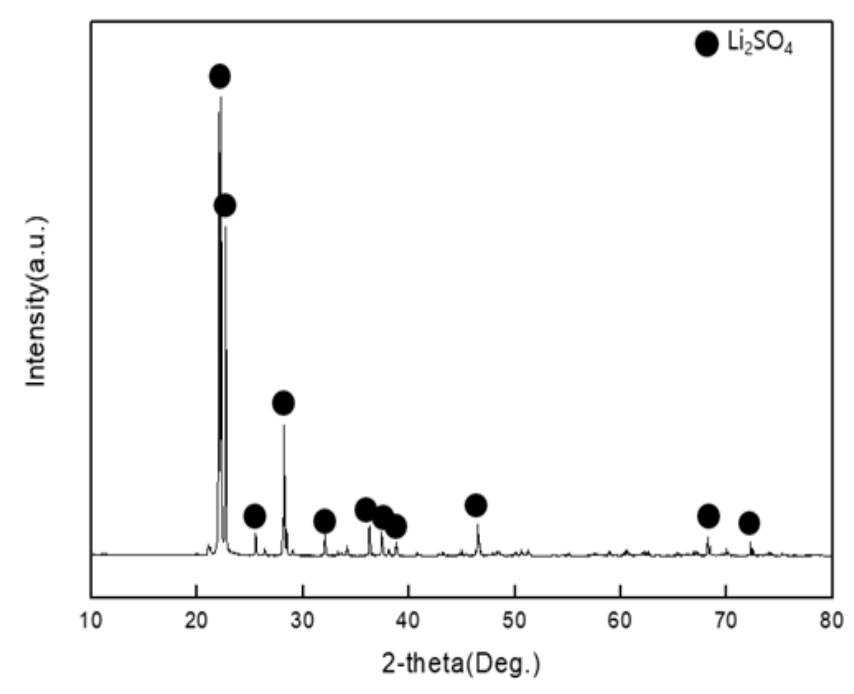

Fig. 1. XRD patterns of a raw specimen

The experimental apparatus used for thermal reaction of $\mathrm{Li}_{2} \mathrm{SO}_{4}$ was an electric furnace that block outside atmosphere, and controls temperature in heat caused by sending electric current 
to SIC heater inside the electric furnace. The reactor is where crucible and specimen are inserted, and is blocked from outside to facilitate atmosphere control. Coolant flows inside the cover of electric furnace to maintain low temperature and prevent parts being damaged by high temperature, and also to prevent equipment deformation due to high temperature. The crucible used in the experiment was alumina crucible, which isn't reactive against the specimen, so it can only induce reaction among the raw specimen, additive, and gas.

\section{RESULTS AND DISCUSSION}

This study aims to recover lithium from $\mathrm{Li}_{2} \mathrm{SO}_{4}$, concentrated through nitric acid method, through carbonation in the form of $\mathrm{Li}_{2} \mathrm{CO}_{3}$. The overall process of experiment is displayed in Fig. 2. The overall process includes phase change from concentrated $\mathrm{Li}_{2} \mathrm{SO}_{4}$ to $\mathrm{Li}_{2} \mathrm{CO}_{3}$ through carbonation, removal of impurities and residual carbon powder from $\mathrm{Li}_{2} \mathrm{CO}_{3}$ through water leaching and decompression filtration, and recovery of $\mathrm{Li}_{2} \mathrm{CO}_{3}$ powder by drying collected $\mathrm{Li}_{2} \mathrm{CO}_{3}$ solution.

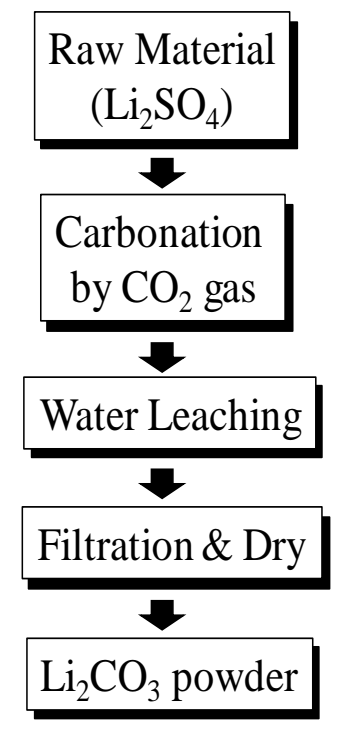

Fig. 2. A flow diagram of fabrication process of lithium carbonate

After adding carbon powder to produce $\mathrm{Li}_{2} \mathrm{CO}_{3}$ from $\mathrm{Li}_{2} \mathrm{SO}_{4}$, a phase change experiment to $\mathrm{Li}_{2} \mathrm{CO}_{3}$ was conducted through the thermal reaction of $\mathrm{CO}_{2}$ gas. Phase change from $\mathrm{Li}_{2} \mathrm{SO}_{4}$ through carbonation occurs in $\mathrm{Li}_{2} \mathrm{CO}_{3}$ according to the reaction formula seen below, and the thermodynamics program, HSC Program, confirmed that reaction started to occur at $600^{\circ} \mathrm{C}$.

$$
\begin{aligned}
& \mathrm{Li}_{2} \mathrm{SO}_{4}+4 \mathrm{C} \rightarrow \mathrm{Li}_{2} \mathrm{~S}+4 \mathrm{CO}, \Delta \mathrm{G}^{\circ} \text { at } 600^{\circ} \mathrm{C} \leq 0 \\
& \mathrm{Li}_{2} \mathrm{~S}+\mathrm{CO}_{2} \rightarrow \mathrm{Li}_{2} \mathrm{CO}_{3}+\mathrm{SOx}, \Delta \mathrm{G}^{\circ}{ }_{\text {at } 600^{\circ} \mathrm{C}} \leq 0
\end{aligned}
$$

The power after carbonation reaction was analyzed through XRD analysis, and the change of phase in $\mathrm{Li}_{2} \mathrm{SO}_{4}$ was verified based on the result of XRD analysis. XRD analysis result on phase change based on temperature is displayed in Fig. 3. Compared to the XRD analysis result of raw specimen, $\mathrm{Li}_{2} \mathrm{CO}_{3}$ phase did not appear at $800^{\circ} \mathrm{C}$, but $\mathrm{Li}_{2} \mathrm{SO}_{4}$ phase changed to $\mathrm{Li}_{2} \mathrm{CO}_{3}$ completely at $900^{\circ} \mathrm{C}$.

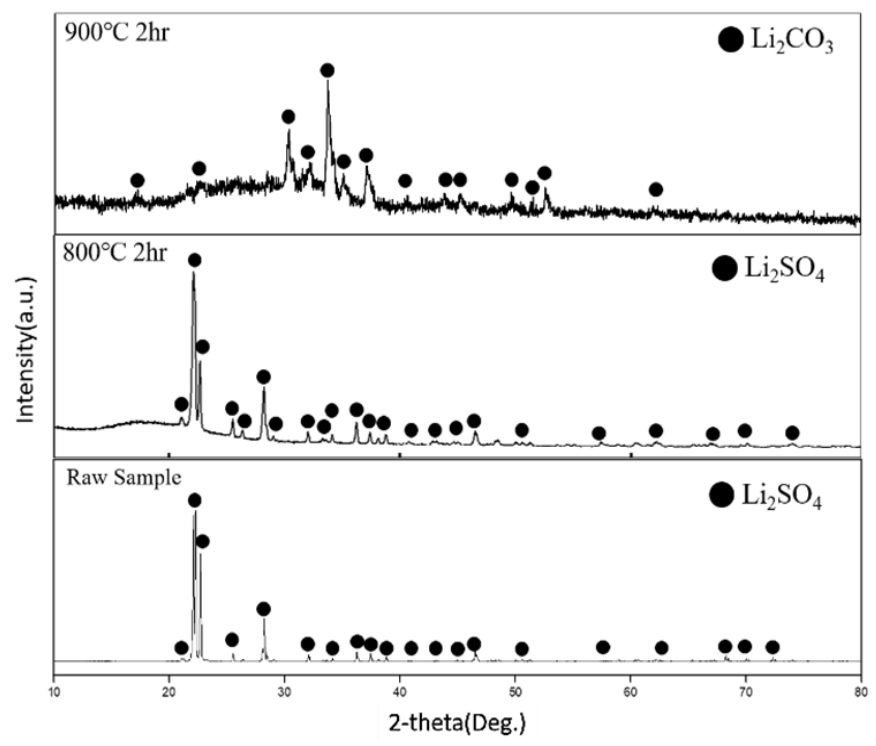

Fig. 3. XRD pattern of formation of lithium carbonate on the effect of temperature

An experiment to draw the optimum water leaching condition was conducted for separation and recovery of $\mathrm{Li}_{2} \mathrm{CO}_{3}$, by using distilled water ratio as the variable. Performance of water leaching was confirmed through Li content in the powder that was separated through decompression filtration after water leaching in ICP analysis result, and ICP-OES (Inductively Coupled Plasma Optical Emission Spectroscopy) analysis result is displayed in Table 1 below. Based on ICP analysis, Li content in powder was $2230 \mathrm{ppm}$ at 1:10 ratio of powder and distilled water, and no $\mathrm{Li}$ was detected at 1:30 ratio. Therefore, the optimum ratio between powder and distilled water after carbonation was confirmed to be $1: 30$.

Table 1. Lithium content in powder after filtration according to ration of powder and distilled water

\begin{tabular}{|c|c|c|c|}
\hline & $\mathbf{1 : 1 0}$ & $\mathbf{1 : 2 0}$ & $\mathbf{1 : 3 0}$ \\
\hline $\begin{array}{c}\text { Lithium, } \\
\text { ppm }\end{array}$ & 2230 & 139 & N/D \\
\hline
\end{tabular}

The $\mathrm{Li}_{2} \mathrm{CO}_{3}$ solution, collected through water leaching and filtration, was recovered as $\mathrm{Li}_{2} \mathrm{CO}_{3}$ through drying. A dryer was used at $100^{\circ} \mathrm{C}$ for 24 hours, and the images of $\mathrm{Li}_{2} \mathrm{CO}_{3}$ solution prior to drying and $\mathrm{Li}_{2} \mathrm{CO}_{3}$ powder after drying are displayed in Fig. 4. 


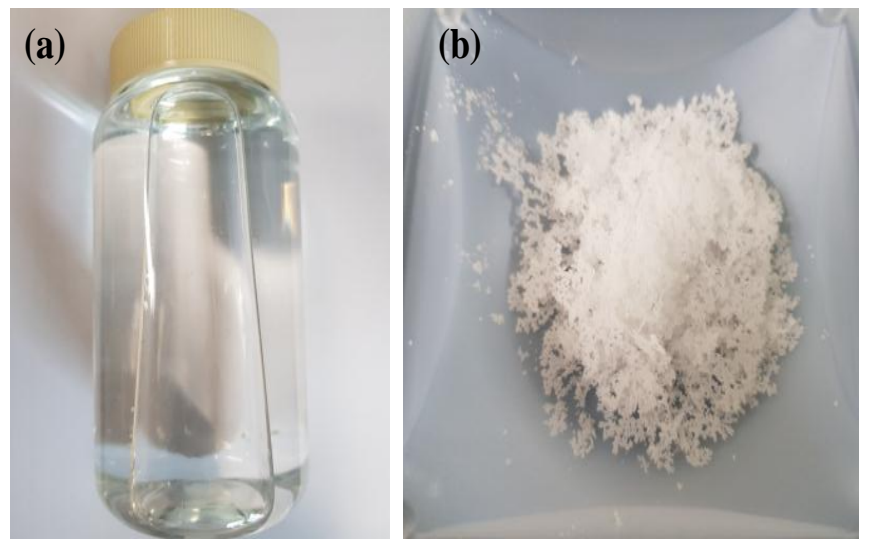

Fig. 4. Lithium carbonate in distilled water (a) and power form of lithium carbonate after drying (b)

Purity of recovered $\mathrm{Li}_{2} \mathrm{CO}_{3}$ was measured by analyzing the contents of the elements of 40 minerals in ICP-OES analysis, and Table 2 displays 50 elements that are analyzed for purity. As a result of purity analysis, 7 elements of impurities were detected in recovered $\mathrm{Li}_{2} \mathrm{CO}_{3}$, including calcium, potassium, magnesium, sodium, phosphorus, silicon, and strontium, at the total content of $656.5 \mathrm{mg} / \mathrm{L}$. Therefore, with $0.066 \%$ impurities in recovered $\mathrm{Li}_{2} \mathrm{CO}_{3}$, the purity of finally recovered $\mathrm{Li}_{2} \mathrm{CO}_{3}$ was $99.93 \%$.

Table 2. ICP analysis of recovered $\mathrm{Li}_{2} \mathrm{CO}_{3}$ powder

\begin{tabular}{|c|c|c|c|}
\hline \multicolumn{4}{|c|}{40 elements for ICP analysis } \\
\hline \hline $\mathrm{Al}$ & $\mathrm{Fe}$ & $\mathrm{Nb}$ & $\mathrm{Sn}$ \\
\hline $\mathrm{As}$ & $\mathrm{Ga}$ & $\mathrm{Ni}$ & $\mathrm{Sr}$ \\
\hline $\mathrm{B}$ & $\mathrm{Ge}$ & $\mathrm{P}$ & $\mathrm{Ta}$ \\
\hline $\mathrm{Ba}$ & $\mathrm{In}$ & $\mathrm{Pb}$ & $\mathrm{Ti}$ \\
\hline $\mathrm{Be}$ & $\mathrm{K}$ & $\mathrm{R}$ & $\mathrm{Tl}$ \\
\hline $\mathrm{Ca}$ & $\mathrm{Li}$ & $\mathrm{Re}$ & $\mathrm{V}$ \\
\hline $\mathrm{Cd}$ & $\mathrm{M}$ & $\mathrm{Sb}$ & $\mathrm{W}$ \\
\hline $\mathrm{Co}$ & $\mathrm{Mn}$ & $\mathrm{Sc}$ & $\mathrm{Y}$ \\
\hline $\mathrm{Cr}$ & $\mathrm{Mo}$ & $\mathrm{Se}$ & $\mathrm{Zn}$ \\
\hline $\mathrm{Cu}$ & $\mathrm{Na}$ & $\mathrm{Si}$ & $\mathrm{Zr}$ \\
\hline
\end{tabular}

\section{CONCLUSION}

This study was conducted to separate and recover $\mathrm{Li}_{2} \mathrm{CO}_{3}$ through water leaching after producing $\mathrm{Li}_{2} \mathrm{CO}_{3}$ from $\mathrm{Li}_{2} \mathrm{SO}_{4}$, which was produced and concentrated from spodumene using sulfuric acid method, through carbonation. In carbonation, a phase change was performed by adding $\mathrm{CO}_{2}$ gas and carbon powder, and $\mathrm{Li}_{2} \mathrm{CO}_{3}$ powder with the final purity of $99.93 \%$ was produced through water leaching, decompression filtration, and drying.

\section{ACKNOWLEDGMENTS}

This work was supported by a Research Grant of Pukyong National University (2019)

This article was reconstructed by using the data from DongHyeon Choi's master's thesis in 2020.

\section{REFERENCES}

[1] N. Ding, X. W. Ge and C. H. Chen, A new gel route to synthesize $\mathrm{LiCoO}_{2}$ for lithium-ion batteries, Mater. Res. Bull. 40 (2005)

[2] M. K. Jeong, C. S. Hwang and C. S. Choi, Characterization of $\mathrm{LiCoO}_{2}$ Synthesized via Structural and Compositional Variations of Precursors Prepared by Precipitation, CLEAN TECHNOLOGY. 12 (2006)

[3] J. Khanderi and J. J. Schneider, A single source Co/Li/O organometallic precursor for nano-crystalline $\mathrm{LiCoO}_{2}$. Synthesis, formation pathway and its electrochemical performance, Eur. J. Inorg. Chem. (2010)

[4] J. H. Moon, J. E. Ahn, H. J. Kim, S. H. Sohn, H. W. Lee and H. S. Kim, Recovery of Cobalt from Waste Cathode Active Material Using Organic Acid, Applied Chemistry. 16 (2012)

[5] C. K. Lee, D. H. Yang and C. Y. Suh, Preparation of \$LiCoO_2\$ from Spent Lithium Ion Batteries as a Cathodic Active Material, J. KSMER. 39 (2002)

[6] B. Swain, J. Jeong, J. C. Lee, G. H. Lee and J. S. Sohn, Hydrometallurgical process for recovery of cobalt from waste cathodic active material generated during manufacturing of lithium ion batteries, J. Power Sources. 167 (2007)

[7] N. Ding, X. W. Ge and C. H. Chen, A new gel route to synthesize $\mathrm{LiCoO}_{2}$ for lithium-ion batteries, Mater. Res. Bull. 40 (2005)

[8] J. W Ahn, H. J Ahn, S. H Son, K. W Lee, 2012: Solvent Extraction of Ni and Li from Sulfate Leach Liquor of the Cathode Active Materials of Spent Li-ion Batteries by PC88A, J. of Korean Inst. of Resources Recycling 21, pp.58-64.

[9] J. J Lee, J. D Chung, 2010: A Study on the Cobalt and Lithium Recovery from the Production Scraps of Lithium Secondary Battery by High Efficient and Ecofriendly Method, J. of Korean Inst. of Resources Recycling, 19, pp.51-60.

[10] D. W Kim, S. T Jang, 2013: Recovery of Lithium and Leaching Behavior of NCM Powder by Carbon Reductive Treatment from $\mathrm{Li}(\mathrm{NCM}) \mathrm{O}_{2}$ System Secondary Battery Scraps, J. of Korean Inst. of Resources Recycling, 22, pp.62-69.

[11] M. K. Jeong, C. S. Hwang and C. S. Choi, Characterization of $\mathrm{LiCoO}_{2}$ Synthesized via Structural and Compositional Variations of Precursors Prepared by Precipitation, CLEAN TECHNOLOGY. 12 (2006) 
International Journal of Engineering Research and Technology. ISSN 0974-3154, Volume 13, Number 6 (2020), pp. 1369-1372

(C) International Research Publication House. https://dx.doi.org/10.37624/IJERT/13.6.2020.1369-1372

[12] J. Khanderi and J. J. Schneider, A single source $\mathrm{Co} / \mathrm{Li} / \mathrm{O}$ organometallic precursor for nano-crystalline $\mathrm{LiCoO}_{2}$. Synthesis, formation pathway and its electrochemical performance, Eur. J. Inorg. Chem. (2010)

[13] J. H. Moon, J. E. Ahn, H. J. Kim, S. H. Sohn, H. W. Lee and H. S. Kim, Recovery of Cobalt from Waste Cathode Active Material Using Organic Acid, Applied Chemistry. 16 (2012)

[14] C. K. Lee, D. H. Yang and C. Y. Suh, Preparation of LiCoO2 from Spent Lithium Ion Batteries as a Cathodic Active Material, J. KSMER. 39 (2002) 